\title{
Features of the concept of happiness representation in PR discourse
}

\author{
Alla Petrovna Minyar-Beloroucheva ${ }^{1 *}$, Polina Igorevna Sergienko ${ }^{2}$, Olga Dmitrievna \\ Vishnyakova $^{3}$, Elizaveta Alexandrova Vishnyakova $^{4}$, and Elena Viktorovna \\ Knyazhinskaya ${ }^{1}$ \\ ${ }^{1}$ Lomonosov Moscow State University, History Faculty, Department of Foreign Languages, Moscow, \\ Russia \\ ${ }^{2}$ Lomonosov Moscow State University, Faculty of Foreign Languages and Area Studies, Department \\ of English for Humanities Faculties, Moscow, Russia \\ ${ }^{3}$ Lomonosov Moscow State University, Philological Faculty, Department of English Linguistics, \\ Moscow, Russia \\ ${ }^{4}$ Lev Tolstoy Tula State Pedagogical University, Faculty of Foreign Languages, Department of the \\ English Language, Tula, Russia
}

\begin{abstract}
The article deals with the concept of HAPPINESS in Public Relation discourse (PR discourse). The concept of HAPPINESS refers to one of the most important components of the linguistic worldview of each nation. Analysis of lexical units that verbalize the concept of HAPPINESS through the prism of PR discourse allows us to identify the linguistic features that create images contributing to the promotion of various ideas of PR campaigns especially dealing with food promotion. The desire to be happy is inherent in every person as an integral part of his or her nature. The persons' ideas concerning happiness are included in the life system of their values and express their attitude to the world. The problem of human happiness has long been the most important issue of philosophy but presently of some transdisciplinary areas, PR campaigns included. The conducted study shows that happiness as the supreme good, as the possible and achievable state of human existence, is one of the main concerns of PR discourse. At present the interest in the concept of happiness and how to achieve it is of primary importance for PR councilors, responsible for the goodwill of their companies in the long run. Both at its associative level and linguistically it is achieved by means of connotatively loaded lexical units denoting taste and strong emotions, necessary for the empirical construction of happiness.
\end{abstract}

Keywords: happiness; PR discourse; food; linguistics.

\section{Introduction}

Modern linguistics is noted for the increase of the role of anthropocentric, cultural and cognitive approaches to the study of language which is the primary source of knowledge concerning the conceptual structures of consciousness. Concepts become tangible with the

* Corresponding author: ostvera@mail.ru 
help of words, phrases, utterances and texts. In this connection the preference is given to polysemantic words describing complex concepts.

Unlike the general usage of concept HAPPINESS that correlates with the concepts of hope and fortune in PR discourse [1,2] it is connected with responsible consumption and bringing the good to people.

Recent studies on happiness indicate cultural difference in perception of happiness, motivations to inspire it. Representatives of different cultures perceive it in different ways [3]. The contrast is best illustrated by North American culture in which happiness is apprehended as a personal achievement. In Asian cultural environment happiness is about collective feeling and shared positive affect. The common ground for different cultural settings is food as inherent part of the feeling of happiness. The culture of food consumption has been the subject of continuous studies aimed at revealing the governmental policy [4], food safety [5, 6], customary behavior [7], their attitudes [8, 9] and satisfaction.

\subsection{Hypothesis of the study}

Lexical units denoting taste that are used for the purpose of creating the feeling of happiness are the necessary instruments for evoking sense perceptions that are indispensable for achieving PR goals in the professional discourse.

\subsection{The purpose of the study}

The purpose of the study is to describe the concept of HAPPINESS, taking into account the formal and semantic characteristics of PR discourse representing the given concept. The correlation of lexical units with sense perception contributes to the promotion of PR discourse ideas and subjects.

\section{Methods and methodology}

The methods used in this paper include continuous sampling of PR texts, philological analysis, synthesis and classification. The comparative method allows to discern a cluster of lexical units used in PR discourse that correlate with sense perception and cause the feeling of happiness. Methodological procedures included special methods of linguistic research including semantic, contextual and conceptual analyses.

\section{Results and discussion}

The concept of happiness verbalized by various lexical units is one of the most important concepts denoting the feelings of the people that correlate with their pleasure and satisfaction with the conditions of their life and work, self-realization, delight, prosperity, the achievement of their aims and the fulfillment of their mission. Among the factors that stimulate the evocation of the feeling of happiness is taste that incites the emotional uplift in the hearts and souls of the recipients by the appropriate linguistic means as referred to certain associations.

Studying the concept of happiness through the prism of PR discourse allows us to understand the ways of creating individual and collective feeling of happiness that fosters the effective implementation of the tasks posed by PR campaigns. PR discourse can be defined as the message transmission aimed at informing both public and members of different organizations about something to develop two-way communication in society to organize and maintain social harmony [10] to influence other companies and organizations. Thus, PR 
discourse primarily embraces the types of communication. The success of PR campaigns to promote certain ideas and achieve a set of objectives is gained by positive image making [2] that depends upon such factors as: linguistic and extra-linguistic and emotional-evaluative, being unique in its representation for every PR campaign. Thus, the emphasis is made on creating a positive image of every communicative strategy that inspires hope, trust and confidence among the consumers. Such positive emotions are connected with the feeling of happiness.

The concept of happiness having received special attention in the contemporary scholarly works [11] is verbalized in the polysemantic word "happiness" denoting "a state of wellbeing and contentment: joy that means the emotion evoked by well-being, success, or good fortune or by the prospect of possessing what one desires: delight"'. Another meaning of this word is "the expression or exhibition of such emotion: gaiety; a state of happiness or felicity: bliss". It is also understood as "a source or cause of delight; a pleasurable or satisfying experience". Finally, it denotes "felicity, aptness a striking happiness of expression. In the obsolete sense happiness defines good fortune: prosperity [12]. From the dictionary definition, it is clear that the concept of happiness expands its meaning due to such synonyms as joy, delight, gaiety, felicity, bliss and even prosperity. In other words, the concept of happiness represented by means of certain lexical units, concerns with feelings that come over people when they know that life is good.

The feeling of happiness, which PR practitioners promote to create company's positive images and their products, are fixed in consumers' individual and collective consciousness. The feeling of happiness is inextricably linked with the perception of taste. Of the four main classical types of taste: salty, sweet, bitter, sour, psychologists consider that sweet taste is coupled with happiness, which is connected with festivities and feasts created by the festive foodstuff that promote PR campaigns images and products:

Festive favourite Quality Street this year features the same selection of sweets as 2019. $<\ldots>$ Meanwhile, Quality Street Intrigue, a premium range of boxed chocolates inspired by classic Quality Street flavours, offers two delicious varieties: Salted Caramel Truffles and Praline Truffles.

There is also a debut Christmas Collection from Dairy Box, which offers a tempting range of seasonal flavours including gingerbread and Christmas pudding.

We hope that our festive range will bring those extra moments of pleasure to the season, whether that's finding the perfect stocking stuffer with one of our giant tubes, counting down the days with a delicious advent calendar treat $<\ldots>$ [13].

All the lexical units denoting feasts, holidays as well as festive food are associated with happiness, and this premise is successfully used by PR practitioners in the course of branding development, especially in terms of public opinion creation influence and PR companies' corporative culture involvement.

Everything that is delicious and healthy is considered to be good. Positive emotions produced by delicious and healthy food create the feeling of happiness. It should be stated that everything that PR texts represent concerning food evokes the feeling of happiness. Examples of healthy food being synonymous to happiness press releases of Nestle company include:

Founded in 2015, Freshly delivers a menu of fresh, chef-cooked meals to customers across the country, breaking down the barriers to healthy eating by delivering nutrition and convenience at scale.

Our mission is to make eating healthy easy by bringing nutritious, high quality meals directly to customers' homes. <...> Developed by chefs and nutritionists, the menu features better-for-you versions of classic comfort foods with smart ingredient swaps [14].

Happiness is also associates in PR texts with delight and joy: 
With Nescafé, Nespresso and Starbucks, Nestlé now has the best coffee portfolio to delight consumers around the world.

Customers around the world will be able to enjoy their favorite Starbucks coffee at home when the products will become widely available in grocery stores and major online platforms [15].

The given sentences are dominated by the lexical units that evoke the taste of sweet, introducing the positive assessment and attitude to the promoted product. The taste of sweetness associated with something pleasant create the feeling of happiness. Happy people are easier to convince and win over to PR side.

\section{Conclusion}

Summing up, it should be noted that the concept of HAPPINESS is verbalized via connotatively loaded lexical units to create the atmosphere that is necessary for the promotion of both the companies and their products. By creating a lasting feeling of happiness, lexical units are fixed and associated with specific PR actions, which guarantee the sustainable perception of the companies both by the public and businesses, due to the linguistic means of their representation. Thus, in the course of creating an atmosphere and feeling referred to happiness language serves as a tool of dissemination and consolidation in individual and mass consciousness.

\section{References}

1. A. Minyar-Beloroucheva, P. Sergienko, E. Vishnyakova, O. Vishnyakova, European Proceedings of Social and Behavioural Sciences, Future Academy (online), 97(TILT), 539-547 (2020). https://doi.org/10.15405/epsbs.2020.12.02.72

2. L. Tam, J.-N. Kim, J.E. Grunig, J.A. Hall, J. Swerling, Journal of Marketing Communications (2020). https://doi.org/10.1080/13527266.2020.1851286

3. J. F. Helliwell, R.Layard, J. D. Sachs, World happiness report (Sustainable development solutions network, New York, 2019). Accessed on: February 17, 2021. [Online]. Available: https://happiness-report.s3.amazonaws.com/2020/WHR20.pdf

4. I. Boldyreva, O. Andryushchenko, A. Nikitaeva, Z. Udalova, J. Rudash, Journal of Environmental Management and Tourism, 8(4(20)), 642-647 (2017). Accessed on: February 17, 2020 [Online]. Available: https://www.researchgate.net/publication/321888971_The_agricultural_production_an d_food_industry_development_trends_in_the_context_of_food_security_of_Russia

5. M. Feltes, A. Arisseto-Bragotto, J. Block, Food Quality and Safety, 1(2), 13-27 (2017). Accessed on: February 17, 2021 [Online]. Available: https://www.researchgate.net/publication/316630929_Food_quality_foodborne_diseases_and_food_safety_in_the_Brazilian_food_industry

6. E. Massicotte, S.-M. Deschênes, P.L. Jackson, Eating and weight disorders: EWD, 24(4), 693-704 (2019). https://doi.org/10.1007/s40519-019-00706-8

7. J. P. Vigna, E.W. Mainardes, Revista Brasileira de Marketing, 18(3), 101-126 (2019). https://doi.org/10.5585/remark.v18i3.16368

8. M. Yormirzoev, R. Teuber, T. Li, British Food Journal, 121(2), 371-385 (2019). https://doi.org/10.1108/BFJ-02-2018-0088.

9. D. Karaosmanoğlu, J. Ethn. Food, 7, 11 (2020). https://doi.org/10.1186/s42779-02000049-1 
10. O. Vishnyakova, A. Minyar-Beloroucheva, P. Sergienko, E. Vishnyakova, Harmonizing different cognitive styles through reading, in Conference Proceedings of the 5th International e- Conference on Studies in Humanities and Social Sciences. Belgrade, Serbia, 17-30 (2020). http://dx.doi.org/10.32591/coas.e- conf.05.02017v

11. A. Ejrnaes, B. Greve, International Journal of Social Welfare, 26(3), 206-217 (2017). http://dx.doi.org/10.1111/ijsw.12233

12. Merriam-Webster Dictionary (n.d.). Accessed on: February 14, 2021. [Online]. Available: https://www.merriam-webster.com/dictionary

13. Nestle, (KitKat) Santa's coming to town! Nestlé unwraps its seasonal range for Christmas 2020. Press release (2020). Accessed on: February 17, 2021. [Online]. Available: https://www.nestle.co.uk/en-ie/node/452716

14. Nestle, Nestlé USA acquires Freshly, a pioneer in healthy prepared meals (2020). Accessed on: February 17, 2021. [Online]. Available:

https://www.nestle.com/media/pressreleases/allpressreleases/nestle-usa-acquiresfreshly

15. Nestle, Nestlé announces the global launch of a new range of Starbucks products to enjoy at home (2019). Accessed on: February 17, 2021. [Online]. Available: https://www.nestle.com/media/pressreleases/allpressreleases/global-launch-newstarbucks-products 